Research

\title{
An exploratory study of community factors relevant for participatory malaria control on Rusinga Island, western Kenya Pamela Opiyo $^{1}$, W Richard Mukabana ${ }^{2}$, Ibrahim Kiche ${ }^{3}$, Evan Mathenge ${ }^{2}$, Gerry F Killeen 4,5,6 and Ulrike Fillinger*6
}

Address: ${ }^{1}$ SNV Netherlands Development Organisation, P.O Box 410576, Kasama, Zambia, ${ }^{2}$ School of Biological Sciences, University of Nairobi, P.O. Box 30197-00100 GPO, Nairobi, Kenya, ${ }^{3}$ Christian Children's Fund (CCF), Nairobi, Kenya, ${ }^{4}$ Ifakara Health Research and Development Centre, Public Health Entomology Unit, PO Box 78373, Dar es Salaam, Tanzania, ${ }^{5}$ Swiss Tropical Institute, Department of Public Health and Epidemiology, Socinstrasse 57, Basel, CH-4002, Switzerland and ${ }^{6}$ Durham University, School of Biological and Biomedical Sciences, South Road, Durham DH1 3LE, UK

Email: Pamela Opiyo - pam_ati@yahoo.com; W Richard Mukabana - rmukabana@uonbi.ac.ke; Ibrahim Kiche - ibrahimkiche@yahoo.com; Evan Mathenge - emathenge@kemri.org; Gerry F Killeen - g.f.killeen@durham.ac.uk; Ulrike Fillinger* - ulrike.fillinger@durham.ac.uk

* Corresponding author

Published: 24 April 2007

Malaria Journal 2007, 6:48 doi:10.1 186/1475-2875-6-48

This article is available from: http://www.malariajournal.com/content/6/I/48

(c) 2007 Opiyo et al; licensee BioMed Central Ltd.

This is an Open Access article distributed under the terms of the Creative Commons Attribution License (http://creativecommons.org/licenses/by/2.0), which permits unrestricted use, distribution, and reproduction in any medium, provided the original work is properly cited.

\begin{abstract}
Background: Capacity strengthening of rural communities, and the various actors that support them, is needed to enable them to lead their own malaria control programmes. Here the existing capacity of a rural community in western Kenya was evaluated in preparation for a larger intervention.

Methods: Focus group discussions and semi-structured individual interviews were carried out in I,45 I households to determine (I) demographics of respondent and household; (2) socio-economic status of the household; (3) knowledge and beliefs about malaria (symptoms, prevention methods, mosquito life cycle); (4) typical practices used for malaria prevention; (5) the treatment-seeking behaviour and household expenditure for malaria treatment; and (6) the willingness to prepare and implement community-based vector control.

Results: Malaria was considered a major threat to life but relevant knowledge was a chimera of scientific knowledge and traditional beliefs, which combined with socio-economic circumstances, leads to ineffective malaria prevention. The actual malaria prevention behaviour practiced by community members differed significantly from methods known to the respondents. Beside bednet use, the major interventions implemented were bush clearing and various hygienic measures, even though these are ineffective for malaria prevention. Encouragingly, most respondents believed malaria could be controlled and were willing to contribute to a community-based malaria control program but felt they needed outside assistance.

Conclusion: Culturally sensitive but evidence-based education interventions, utilizing participatory tools, are urgently required which consider traditional beliefs and enable understanding of causal connections between mosquito ecology, parasite transmission and the diagnosis, treatment and prevention of disease. Community-based organizations and schools need to be equipped with knowledge through partnerships with national and international research and tertiary education institutions so that evidence-based research can be applied at the grassroots level.
\end{abstract}




\section{Background}

Malaria imposes a huge burden upon the health and economic development of tropical nations [1-3] and has been identified as a major obstacle towards achieving several of the health-related Millennium Development Goals $[3,4]$. The disease causes widespread premature death and suffering, imposes financial hardship on poor households, retards economic growth and undermines living standards. The vast majority of the world's malaria burden rests in sub-Saharan Africa (SSA) [5] where it is directly responsible for one in five childhood deaths and indirectly contributes to a sizeable proportion of childhood morbidity and mortality resulting from additional illnesses such as respiratory infections, diarrhoeal diseases, iron-deficiency anaemia and malnutrition [4]. An estimated 8.2 million cases of malaria are reported in Kenya every year, out of a total population of 30 million. In Kenya alone, malaria kills an average of 72 children under five years of age each day [6]. The economic burden of malaria for households can be extremely high. Treatment costs for small-scale farmers in rural Kenya have been estimated to be as high as 7\% of the monthly household expenditure [6], not considering any costs for prevention measures.

Malaria risk and disease burden is inequitably distributed, not only at global and regional levels but also at household level because poor housing, lack of education and access to healthcare services create a vicious cycle of enhanced vulnerability to malaria due to increased exposure, high household medical costs, reduced ability to pay for treatment, and so on $[6,7]$. Decisions for prevention or treatment are made depending on economic ability of the household, perceived susceptibility and assessment of consequences. Furthermore, malaria transmission is often facilitated because environmental degradation, poor drainage and clearing of vegetation readily promote the proliferation of mosquito species such as Anopheles gambiae which propagates itself in sunlit, transient water bodies, notably artificial habitats associated with human activities [8-12]. Malaria, poverty and environmental change are inextricably linked and remain closely associated across most of Africa [13].

Rural areas have always been a major challenge for disease control worldwide, but the involvement and active participation of communities has been identified as a key factor for success in these environments [14-18]. Malaria remains robustly endemic in most rural communities of SSA so a central aim of the Roll Back Malaria Partnership (RBMP) is to strengthen the local capacities of communities to identify malaria as one of their main health problems and then take the lead in developing and implementing solutions to these problems in partnership with different actors such as non-governmental organiza- tions providing organizational support and research institutions acting as technical consultants [19-24]. In the past, malaria was predominantly viewed only as a biomedical problem, however, successful disease control at the community level needs to take the human behaviour, sociocultural and economic context into account in order to successfully impact the disease through active participation and changing of risk behaviours [22,25]. These factors, together with the experienced obstacles of earlier vertical, top-down malaria eradication programs, have contributed to the current emphasis on community-based strategies $[22,26]$.

Although, considerable difficulties have been reported in conducting community-based disease control [27-30] there is a large evidence base where such horizontal approaches have been successful because of a true partnership between the community and programme staff. Key elements of these programmes are the generation of a feeling of empowerment, local ownership and responsibility $[19,31]$ and the application of action-oriented and participatory approaches [23,32]. Extended project periods beyond the usual research cycles of three to five years are also necessary to establish [23] and evaluate communitybased interventions since the modification of attitude and behaviour may take years to accomplish [28]. Successful examples of programmes with community participation include the control of dengue [28,31], dracunculiasis $[33,34]$, onchocerciasis [35] and urinary schistosomiasis $[36,37]$. In malaria control, specifically in Africa, few of the projects have been truly 'bottom up' community initiated like the Saradidi Rural Health Development Programme, Kenya [38], but the term is widely used to refer to community co-operation or acceptance of schemes introduced through health education from outside and reflecting national priorities and targets [23,39]. The vast majority of projects with community involvement target the improvement of treatment-seeking behaviour, access to prompt diagnosis and treatment through training of community health workers and shop keepers $[26,27,40-$ $46]$ and the distribution and coverage with insecticidetreated nets (ITNs) $[43,47]$. Relatively few projects show community-led vector control that goes beyond personal protection measures e.g. environmental modifications and larviciding [48-52].

The study presented here was implemented on Rusinga Island in Lake Victoria, Suba District, western Kenya as part of the Rusinga Malaria Project (RMP) of the Rusinga Island Child \& Family Programme (RICFP), a local community based organization (CBO) affiliated to the international non-governmental (NGO) organization Christian Children's Funds - Kenya (CCF-K). Here community members organized in the RICFP identified malaria as a major threat in their daily life and felt the 
need to take action to reduce the malaria burden on the island. As a consequence, community members and staff of CCF-K approached locally-based researchers for assistance in their fight against malaria on Rusinga, acknowledging that the CBO's (and NGO's) knowledge on how to tackle the problem was insufficient [20].

The authors propose that a community-implemented malaria control programme can only be successful and, even more importantly, sustainable if the community considers malaria to be one of their major problems and have the knowledge and skills to participate in its prevention and programme evaluation. The initiation of the RMP and subsequent collaborations already represents a first step toward encouraging new malaria prevention behaviour. Community leaders, public health workers and representatives of various organizations working on health-related issues in the area have identified a great need for training and access to up-to-date information and technical support [20].

As a first step, therefore, it needed to be established how much local people understood about the existing malaria problem on Rusinga, assess their socio-economic background and create awareness for the ongoing project while sensitizing community members for active participation. In order to do this, focus group discussions (FGD) and semi-structured individual interviews (knowledge, attitude and practice (KAP) surveys) were carried out to determine socio-economic and behavioural baselines to identify indicators for monitoring programme effectiveness [53], and to reveal the perceptions, misconceptions and practices of malaria control, thus yielding important information needed to plan and revise training activities, develop locally appropriate education material and design effective methods with the ultimate goal to encourage new malaria prevention behaviours.

\section{Methods}

\section{Study area}

Rusinga Island $\left(0^{\circ} 35^{\prime}-0^{\circ} 44^{\prime}\right.$ South; $34^{\circ} 11^{\prime}-34^{\circ} 22^{\prime}$ East; altitude $1,100 \mathrm{~m}$ ) is $42 \mathrm{~km}^{2}$ in area and is the second largest island in Lake Victoria. Due to its close proximity to the mainland a $200 \mathrm{~m}$ long causeway was constructed in 1983 to link the island with Mbita township, the major trading and the administrative centre of the district. The terrain is extensively deforested and generally rocky and hilly with limited vegetation cover. There are a number of seasonal rivers which contain water only during the rainy season and the lake provides the main water source for the population. Two rainy seasons are typical for the area, the 'long rains' between March and June and the 'short rains' between October and November, but these seasons are unreliable with some years characterised by prolonged dry periods. Malaria transmission fluctuates seasonally but is sustained all year round by the three primary malaria vectors: An. gambiae, Anopheles arabiensis and, to a lesser extent, Anopheles funestus [8,54-56]. As per a census implemented by the end of 2006 during the establishment of a Demographic Surveillance System (DSS), Rusinga island had 24,078 inhabitants which formed 5,425 households and $21 \%$ of the population were children below the age of five (S. Kaneko et al., Nagasaki University, unpublished data). The predominant language spoken is Dholuo.

People living on Rusinga face a multitude of problems. The island has suffered enormous environmental degradation, soil erosion and extended drought conditions in recent years leaving little productive land and few opportunities to make money other than through fishing. Furthermore, construction activities, deforestation, vegetation clearance and poorly planned infrastructure development has led to an increased abundance of mosquito larval habitats [8], notably those suitable for malaria-transmitting Anopheles. The high prevalence of both malaria $(50 \%)$ and HIV/AIDS $(30 \%)$ on the island has been a major impediment to socio-economic development $[57,58]$.

Two government health centres serve Rusinga's population; one in the north-eastern part of the Island and one in Mbita township. Additionally, there are three registered and many unregistered private facilities on the island. Due to the bad condition of the roads public transport is rare especially in the rainy season and it is difficult to reach the health facilities.

\section{The Rusinga Island Child \& Family Programme (RICFP)}

The RMP is implemented through CCF-Kenya's community-based organization RICFP. The CBO has been carrying out development activities on Rusinga for the past 18 years. CCF is an international NGO with the mission to promote the well-being of children by facilitating quality programmes in education, early childhood development, youth, health and nutrition, all including aspects of environmental health and healthy homes [59]. CCF-Kenya is supported by sponsors for 44,000 individual children from around the world and operates in 30 districts of Kenya. The project involves all families of enrolled children in ongoing activities and decision-making processes. CCF-K affiliate CBOs are owned and managed by parentcommittees, selected by neighbourhood groups (jirani) of enrolled parents. The project has divided the island in eight administrative zones. Each jirani group selects a representative to serve in the parent's committee. Using this system, parents identify their own needs, prioritize them, plan, budget and also implement activities. RICFP reaches a total of 4,352 people in 750 families of which 869 are enrolled children aged below 1 to 17 years through direct 
sponsorships. RICFP intends to reach the entire Rusinga community with their educational programmes.

\section{Study design}

Prior to the community-wide KAP survey a series of focus group discussions (FGDs) were conducted in all eight administrative zones with eight to 10 community members per zone, selected by RICFP parent committees. Those focus groups contained of equal numbers of members from CCF-enrolled and non-enrolled families and were gender balanced. The topics that were discussed were signs and symptoms of malaria, causes and mode of transmission and prevention of malaria. The information from these discussions was used to guide formulating the questions for a cross-sectional KAP survey which was conducted from April to July 2004. The study adopted the RMP administrative units of zones to implement a stratified random sampling scheme. A two-stage cluster procedure with zones and households within them as the two levels sampling units were adopted. The households were divided into two categories; the CCF-enrolled and the non-CCF-enrolled households. The sample size depended on the number of CCF-enrolled households as the intention was to interview all these households $(n=750)$. A matching household sample size from the same community was randomly selected from non-CCF-enrolled households. Preference for interview was given to households that had at least one child under five years of age. Therefore, a census was implemented in all the eight zones, recording all families with children under five years of age. From this list, households were randomly selected to match approximately the number of CCF-enrolled households in each zone. A total of 1,500 households were selected for interview.

The study largely used quantitative approaches in data collection through a semi-structured questionnaire consisting of 69 questions, both open ended and closed. While the questionnaire was written in both English and Dholuo, the interviews were conducted in the latter ethnic language.

Pre-tests of the questionnaire were conducted in 14 households and adjustments made accordingly. The interviewers were trained residents of Rusinga Island who were fully familiar with the local language, culture and sensitivities. One questionnaire was administered to one household per compound. Households were defined as a group of individuals sleeping in the same house and depending on the same budget [60]. Because many men on Rusinga are polygamous and live in extended family structures several households usually form a compound and often share in a common pool of resources. For interview, preference was give to the female head of the household because she is typically the care taker of the children and responsible for all household duties. In the event that she was absent at the time of interview either the male head of the household or any child above the age of 12 years was questioned. Interviews were conducted in private to reduce influence of relations. Where occupants were not found on the first visit, two other attempts were made to trace them.

Being part of an integrated development programme at community level, the CCF-enrolled families have been involved in various health training activities including malaria prevention. On the other hand the non-CCFenrolled families have not been exposed to this type of training and health care. The objective here was to investigate whether there was a measurable difference in knowledge, attitude and practice concerning malaria in families that have been exposed to these activities and been embedded in a social network by an established NGO. In general, the study aimed to investigate whether household socio-economic status or demographic characteristics affect malaria related knowledge, prevention and treatment behaviour and the willingness to participate in a community-based programme. The questionnaire was structured into the following topics: (1) demographics of respondent and household; (2) socio-economic status of the household; (3) knowledge and beliefs about malaria (symptoms, prevention methods, mosquito life cycle) (4) typical practices toward malaria prevention; (5) the treatment-seeking behaviour and household expenditure for malaria treatment; and (6) the willingness to prepare and implement community-based vector control.

\section{Ethical considerations}

The institutional ethical clearance was granted by the joint University of Nairobi - Kenyatta National Hospital ethical review committee (protocol approval number P102/7/ 2004). In addition, permission was obtained from the district authorities and community leaders. Individual interviews were only started after the purpose of the study had been clearly explained to the participant and an informed consent form was read and signed.

\section{Data analysis}

The semi-structured part of the questionnaire was coded after completion of the survey. All data were entered and analysed using the statistical software package for social sciences (SPSS) Version 14.0. Analyses of the outcome of variables were performed excluding non-responders or missing data points, therefore only valid percentages of the responses were accepted which leads to the fact that the total number of respondents ( $\mathrm{n}$ ) varied between questions. A socio-economic index [61] based on household assets was created using Principal Component Analysis (PCA) [62]. The final PCA was based on 13 asset variables (sofa set, bicycle, radio, television set, solar panel, genera- 
tor, car battery, mobile phone, boat, fishing net, number of cows, goats and chicken) that were identified by community members during FGDs and explained $27 \%$ of the variability in the 13 variables. Each interviewed household was assigned to a socio-economic quintile (most poor; very poor; poor; less poor; least poor) according to PCA. Chi-squared tests $\left(\chi^{2}\right)$ were used to examine whether the distribution of individuals/households among the categories of one variable is independent of their distribution among the categories of the other. Logistic regression analyses (backward stepwise) were used to explain variations in responses to questions about knowledge and behaviour towards malaria and its control (e.g. bednet ownership and bednet use, knowledge of mosquitoes as malaria vector) based on socio-economic and demographic indices.

\section{Results \\ Response rate}

Of the 1,500 households selected for the survey residents from 1,451 households were interviewed (97\% response rate), 701 households being CCF-enrolled and 750 households being non-CCF-enrolled. Interviewed households were equally distributed over the island with an average of $12.5 \%$ (95\% C.I. $=10.6-14.4)$ of all respondents interviewed in each zone. There were 1,054 female and 397 male respondents.

\section{Socio-demographic characteristics of respondents}

The mean age of respondents was 34.5 years $(95 \%$ C.I. $=$ $33.9-35.2$ ) and $70 \%$ were within the age range of 21.5 to 47.5 years. The average household on Rusinga had 6.2 household members $(95 \%$ C.I. $=6.1-6.3)$ and 4 children (95\% C.I. $=3.9-4.2) ; 1.7$ children below the age of five years $(95 \%$ C.I. $=1.7-1.8)$. Nearly all respondents $(98 \%)$ had lived on Rusinga for most of their life. In 32\% of all households, the household head was polygamous with two or more wives. $2 \%$ of wives were 18 years or less $(n=$ $23)$, some as young as 14 years old.

Table 1 shows how some of the demographic and economic variables are distributed in households of different socio-economic level. Notably, the majority of the female headed households were in the poorest socio-economic quintiles. This distribution differs significantly from the male-headed households. Of all respondents, only $21 \%$ were educated beyond primary school, among whom $1.6 \%$ attained tertiary-level education (Table 2). There was a significant difference in the educational level between women and men, with more men educated beyond primary level and a higher percentage of women without any formal education (Table 2). Unsurprisingly, more highly educated respondents were found in wealthier households (Table 1). CCF-enrolled households belonged predominantly to the lower socio-economic lev- els including $76 \%$ of all respondents without formal education (68 out of 90 ) and only $4 \%$ of respondents had a college degree (one out of 23), indicating that the CCF programme's targeting strategy is well implemented. Interestingly, households of higher socio-economic status were also characterized by a higher number of household members, children and wives. Fishing and small-scale businesses like fish mongering and vegetable sales were the most common income generating activities undertaken by the residents of Rusinga; fishing primarily done by men ( $62 \%$ of male respondents) and small-scale businesses by women ( $48 \%$ of female respondents). A sizeable proportion of women (32\%) did not work outside the home (housewives) and depended on the income of their husbands (Table 2). In 30\% of households fishing ( $\mathrm{n}=$ $472)$ and small-scale businesses $(n=426)$ were mentioned as main sources of income, respectively. $12 \%$ of households $(n=179)$ received their main income from larger businesses and notably $8 \%(\mathrm{n}=116)$ of the households depended primarily on remittances from relatives outside Rusinga (Table 1). Formal employment as major income source was primarily found in households of the highest socio-economic status while most of the labourers for small wage income were found to belong to the poorest households (Table 2). The average monthly budget per household was reported to be Kenya Shillings (KShs) $5,360(95 \%$ C.I. $=5,221-5,505)$ which equals US Dollars (\$) 72.5 (KShs $72=\$ 1$ ) but only $8 \%$ of all households (n $=1,312$ ) were able to meet their monthly budget in cash. Notably, the households that were unable to meet their budget were equally distributed over all the socio-economic levels $\left(\chi^{2}=9.8 ;\right.$ d.f. $\left.=4 ; \mathrm{p}=0.056\right)$ indicating that higher socio-economic standard induces higher demand and expectations [60]. The average expenditure that could actually be met by households in terms of cash available was KShs 2,960 (95\% C.I. = 2,848-3,068; S.D.: 2,007); $15 \%$ of all households lived below the poverty line [6] having less than KShs 1,500 (\$21) per months. Households of higher socio-economic status met a significantly higher amount of cash per month (Table 1).

\section{Knowledge and beliefs}

The respondents were asked about the perceived threats for life on Rusinga, most seriously felt diseases, malaria symptoms, most vulnerable groups to malaria infection, mode of parasite transmission and malaria prevention methods known. In FGDs, community members identified five major threats to life on Rusinga which were: droughts, diseases, no access to safe water, witchcraft and dangerous animals like snakes. For the diseases HIV/ AIDS, malaria, diarrhoeal diseases, typhoid and tuberculosis were noted to be most prevalent. In the individual interviews, respondents were requested to rank these threats and diseases in descending order of importance 
Table I: Summary of the socio-demographic characteristics of respondents by socio-economic status

\begin{tabular}{|c|c|c|c|c|c|c|}
\hline \multirow[t]{2}{*}{ Characteristics } & \multirow[t]{2}{*}{ Total $\mathbf{N}$} & \multicolumn{5}{|c|}{ Socio-economic status } \\
\hline & & Most poor (\%) & Very poor (\%) & Poor (\%) & Less poor $(\%)$ & Least poor (\%) \\
\hline Total households interviewed & $145 \mid$ & 19.8 & 20.2 & 19.9 & 20.1 & 30.0 \\
\hline CCF-enrolled households & 701 & 22.0 & 20.4 & 20.7 & 21.7 & 15.4 \\
\hline \multicolumn{7}{|l|}{ Sex of household head $\left(\chi^{2}=86.5\right.$; d.f. $\left.=4 ; p<0.001\right)$} \\
\hline male & 1125 & 16.1 & 18.5 & 19.8 & 21.4 & 24.1 \\
\hline female & 326 & 32.2 & 26.1 & 20.2 & 15.6 & 5.8 \\
\hline \multicolumn{7}{|l|}{ Age of respondent $\left(\chi^{2}=26.5 ;\right.$ d.f. $\left.=12 ; p=0.009\right)$} \\
\hline below 25 & 376 & 19.9 & 20.7 & 17.6 & 20.2 & 21.5 \\
\hline 25 to 34 & 443 & 23.7 & 23.3 & 17.8 & 17.2 & 18.1 \\
\hline 35 to 44 & 301 & 15.0 & 16.3 & 23.3 & 20.9 & 24.6 \\
\hline above 45 & 322 & 18.6 & 19.3 & 22.4 & 23.3 & 16.5 \\
\hline \multicolumn{7}{|c|}{ Educational level of respondent $\left(\chi^{2}=44.9 ;\right.$ d.f. $\left.=12 ; p<0.001\right)$} \\
\hline none & 89 & 24.7 & 25.8 & 23.6 & 19.1 & 6.7 \\
\hline primary & 1039 & 20.8 & 21.4 & 19.5 & 20.1 & 18.2 \\
\hline secondary & 283 & 14.8 & 14.5 & 21.6 & 20.1 & 29.0 \\
\hline college & 23 & 8.7 & 17.4 & 4.3 & 26.1 & 43.5 \\
\hline \multicolumn{7}{|c|}{ Number of household members $\left(\chi^{2}=100.0 ;\right.$ d.f. $\left.=12 ; p<0.001\right)$} \\
\hline 2 to 4 & 384 & 27.1 & 26.3 & 21.6 & 14.3 & 10.7 \\
\hline 5 to 7 & 685 & 21.0 & 20.1 & 18.4 & 18.8 & 21.6 \\
\hline 8 to 10 & 299 & 10.0 & 15.4 & 22.1 & 29.4 & 23.1 \\
\hline more than 10 & 73 & 9.6 & 9.6 & 16.4 & 24.7 & 39.7 \\
\hline \multicolumn{7}{|l|}{ Number children $\left(\chi^{2}=49.7 ;\right.$ d.f. $\left.=8 ; p<0.001\right)$} \\
\hline I to 2 & 396 & 24.7 & 24.7 & 20.7 & 15.9 & 13.9 \\
\hline 3 to 5 & 715 & 20.3 & 21.0 & 18.7 & 19.3 & 20.7 \\
\hline more than 5 & 328 & 12.8 & 13.4 & 21.3 & 27.1 & 25.3 \\
\hline \multicolumn{7}{|c|}{ Number of wives of household head $\left(\chi^{2}=37.3 ;\right.$ d.f. $\left.=8 ; p<0.001\right)$} \\
\hline I wife & 918 & 22.8 & 21.6 & 19.9 & 19.9 & 15.8 \\
\hline 2 wives & 286 & 14.3 & 21.0 & 20.3 & 18.9 & 25.5 \\
\hline more than 2 wives & 154 & 15.6 & 15.6 & 16.9 & 19.5 & 32.5 \\
\hline \multicolumn{7}{|c|}{ Main source of household income $\left(\chi^{2}=99.1\right.$; d.f. $\left.=28 ; p<0.00 I\right)$} \\
\hline unskilled labour & 70 & 28.6 & 24.3 & 30.0 & 11.4 & 5.7 \\
\hline skilled labour (craftsperson) & 16 & 25.0 & 25.0 & 18.8 & 18.8 & 12.5 \\
\hline farming & 73 & 12.3 & 17.8 & 24.7 & 24.7 & 20.5 \\
\hline small scale business* & 426 & 22.8 & 23.9 & 18.3 & 19.2 & 15.7 \\
\hline other business & 179 & 17.9 & 21.8 & 18.4 & 19.6 & 22.3 \\
\hline fishing & 472 & 17.8 & 17.6 & 21.2 & 22.2 & 21.2 \\
\hline Salary/pension for employment & 73 & 4.1 & 12.3 & 16.4 & 19.2 & 47.9 \\
\hline support from relative outside Rusinga & 116 & 27.6 & 19.8 & 12.9 & 19.8 & 19.8 \\
\hline \multicolumn{7}{|c|}{ Monthly expenditure met by households $\left(\chi^{2}=89.5 ;\right.$ d.f. $\left.=12 ; p<0.00 I\right)$} \\
\hline less than I500 KShs & 186 & 34.9 & 26.9 & 17.2 & 16.1 & 4.8 \\
\hline $1500-3000$ KShs & 422 & 20.9 & 23.0 & 20.9 & 18.5 & 16.8 \\
\hline $3000-4500$ KShs & 434 & 15.9 & 19.6 & 22.1 & 20.3 & 22.1 \\
\hline more than $4500 \mathrm{KShs}$ & 232 & 10.3 & 14.7 & 19.0 & 26.7 & 29.3 \\
\hline
\end{tabular}

* fish mongering \& vegetable sales

and to name others that might be felt more important (Figure 1 and 2).

Most respondents felt that diseases are the most important threat to life on Rusinga, followed by drought, lack of access to safe water, witchcraft and dangerous animals; $10 \%$ of all respondents added famine and 5\% added poverty as major threats to the list. Poverty featured in average on rank 5 while famine was ranked 1-3.

Diseases were ranked the most serious problem with 75\% of the respondents ranking it first (Figure 1). Among the diseases, $67 \%$ of respondents ranked malaria as the most dangerous threat (Figure 2). The ranking of HIV/AIDS, typhoid, diarrhoeal diseases and tuberculosis was less consistent. Notably, there was a very indifferent view about the ranking of HIV/AIDS; only $21 \%$ of all respondents ranked it first and second, respectively; 29\% of all respondents ranked HIV/AIDS the least important disease threat in comparison to the others. The ranking of life threats and disease importance did not differ with sex, age, CCF-enrolment status or educational level of the respondent.

Over 95\% of respondents correctly identified headache, sweating, shivering body, high fever, joint pains, loss of appetite and vomiting as malaria symptoms but $88 \%$ of respondents associated malaria also with a running nose, 
Table 2: Differences in education level and occupational activities between men and women

\begin{tabular}{|c|c|c|}
\hline & \multicolumn{2}{|c|}{ Sex of respondent } \\
\hline & male & female \\
\hline \multicolumn{3}{|l|}{ Education $\left(\chi^{2}=76.7 ;\right.$ d.f. $\left.=3 ; p<0.001\right)$} \\
\hline Total N & 393 & 1050 \\
\hline none & $1.3 \%$ & $8.1 \%$ \\
\hline primary & $64.6 \%$ & $75.5 \%$ \\
\hline secondary & $30.0 \%$ & $15.7 \%$ \\
\hline college & $4.1 \%$ & $0.7 \%$ \\
\hline \multicolumn{3}{|l|}{ Occupation $\left(\chi^{2}=800.3 ;\right.$ d.f. $\left.=7 ; p<0.001\right)$} \\
\hline Total N & 391 & 1053 \\
\hline farmer & $9.0 \%$ & $4.6 \%$ \\
\hline labourer & $4.6 \%$ & $2.1 \%$ \\
\hline craftsperson & $2.6 \%$ & $1.1 \%$ \\
\hline fisherfolk & $61.6 \%$ & $2.2 \%$ \\
\hline small-scale business & $4.9 \%$ & $48.0 \%$ \\
\hline business & $5.4 \%$ & $7.8 \%$ \\
\hline formal employment & $5.1 \%$ & $2.1 \%$ \\
\hline none & $6.9 \%$ & $32.2 \%$ \\
\hline
\end{tabular}

$47 \%$ with body rashes and 32\% with blood in sputum. Only $9 \%$ of all respondents mentioned all malaria symptoms correctly.

Regression analysis revealed that correct knowledge of malaria symptoms was dependent on the education level of the respondent but not the age, sex or CCF-enrolment.
Respondents educated beyond primary school level were far more likely to correctly list the malaria symptoms (Table 3).

Among respondents, 96\% knew young children to be at highest risk of suffering from severe malaria and 76\% also knew of pregnant women being at increased risk. But $60 \%$

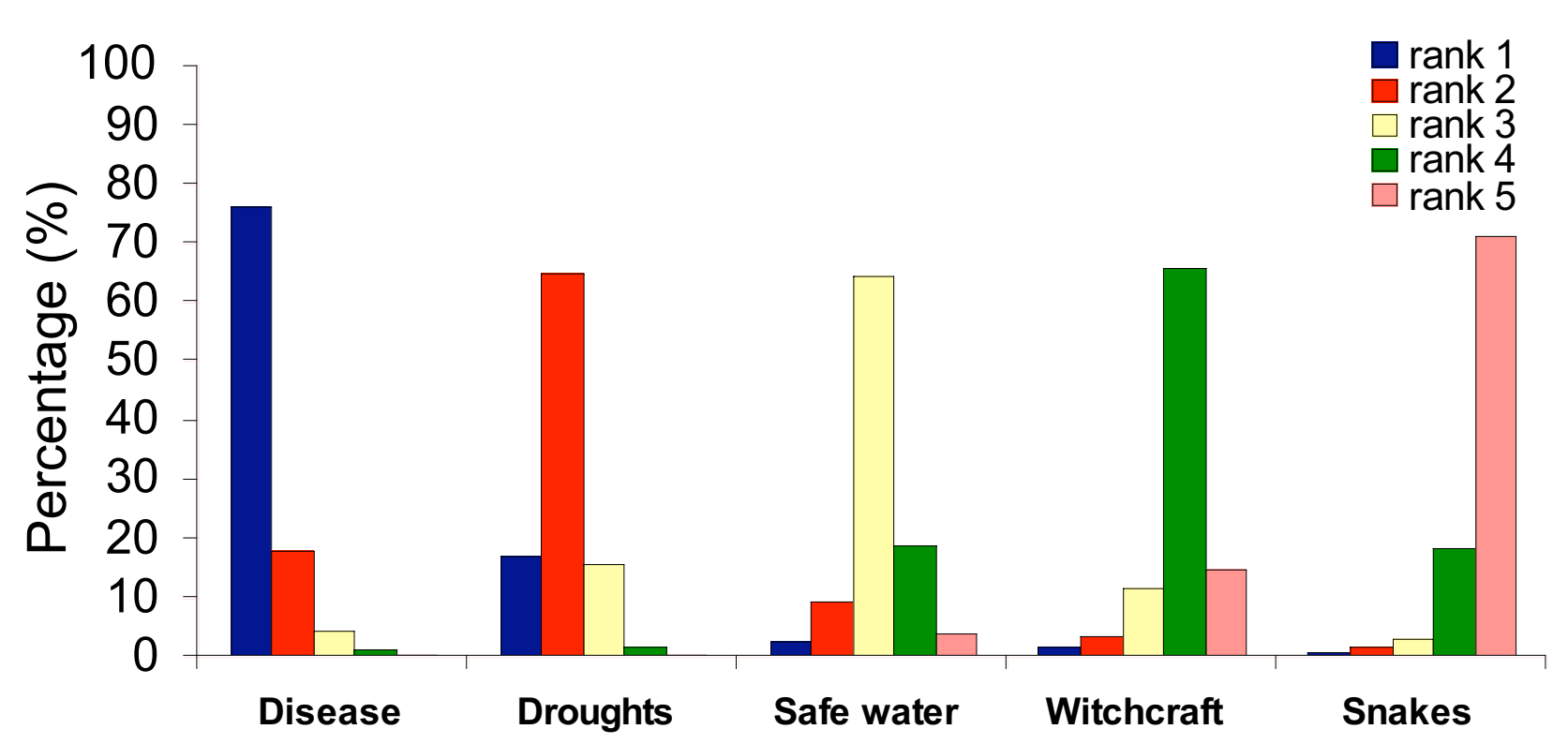

Figure I

Ranks of perceived major threats of live on Rusinga. 


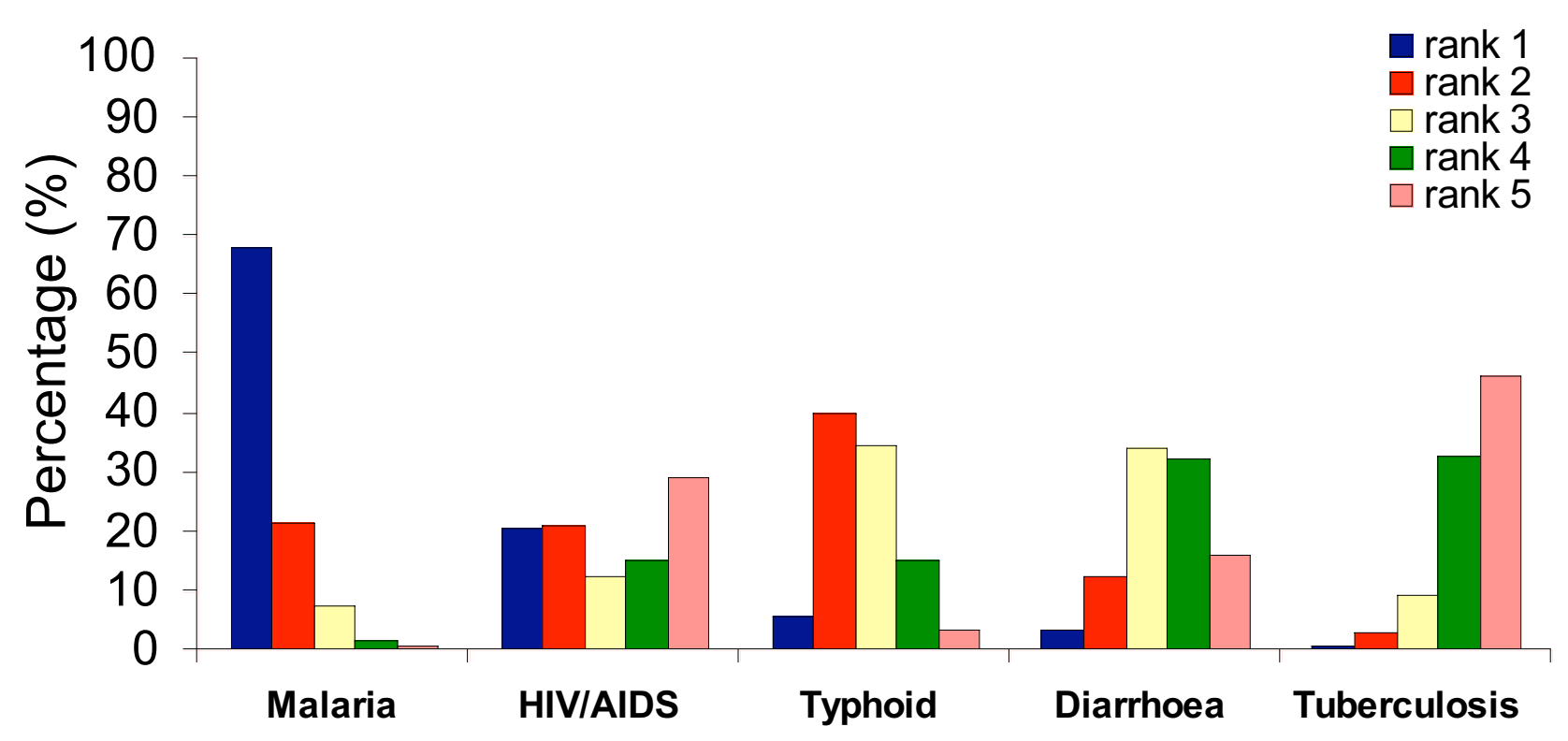

Figure 2

Ranks of perceived importance of diseases on Rusinga.

and $24 \%$ of the respondents also believed that young adults and old people were at high risk of suffering severe malaria, respectively. Other categories of people mentioned were fishermen, those who do not use bednets, tourists, dirty people and those who do not eat a balanced diet.

Of all respondents $(\mathrm{n}=1,445), 5 \%$ did not know what caused malaria. Of those who indicated they knew $(\mathrm{n}=$ 1,378), 91\% mentioned mosquito bites but more importantly only $47 \%$ correctly knew that was the only route for malaria transmission. A large proportion (44\%) of the community believed in a number of causes in addition to mosquito bites and $9 \%$ of all respondents did not mention mosquitoes at all. Other major reasons believed to be responsible for 'catching malaria' (Table 4) were unfavourable weather conditions (cold temperatures, change of weather from cold to hot or vice versa, when one is rained on, sitting in the sun for too long, at times of new moon), lack of hygiene (drinking of dirty water, walking barefoot in dirty environment, unhygienic conditions at home, badly ventilated house, dirty utensils, dust, lack of a latrine or rubbish pit), a bushy compound (planting crops next to the house, bushes and high grass on the compound), food (raw, cold, contaminated or processed food) and body exhaustion (hard labour, no sleep, starving, fever).

Logistic regression analyses were used to identify the variables impacting correct knowledge and misconceptions/ traditional beliefs (Table 5). Education beyond primary school level increased the probability of respondents knowing mosquito bites as the sole cause of malaria by 34 times.

Conversely, community members educated beyond primary school level were less likely to believe that unfavourable weather conditions was responsible for catching malaria. Older age groups were more likely to believe that malaria is caused by unhygienic living conditions and were also more likely not to mention mosquitoes involved in malaria transmission at all. Non-CCFenrolled community members were less likely to mention mosquitoes and more likely to believe in weather as a cause of malaria than CCF-affiliated community members. There were no differences in knowledge and beliefs between men and women.

Table 6 illustrates how, according to community members, malaria parasites enter the human body. A large proportion $(61.8 \%)$ of the respondents $(n=1,439)$ stated mosquito bites only; $7.6 \%$ believed in other ways in addition to mosquito bites, while $10.4 \%$ thought that mosquitoes had no role in the parasite transmission.

Notably, 20.2\% of all respondents declared they do not know; this included respondents that mentioned mosquitoes as cause of malaria earlier. Other beliefs on how one could get infected with malaria parasites included consuming dirty water and food, or through cuts in the skin, 
Table 3: Factors associated with correct biomedical knowledge of malaria symptoms

\begin{tabular}{|c|c|c|c|c|}
\hline \multirow[t]{2}{*}{ Education* } & \multirow[t]{2}{*}{ Odds Ratio } & \multicolumn{2}{|c|}{ 95\% C.I. for Odds Ratio } & \multirow[t]{2}{*}{$P$} \\
\hline & & Lower & Upper & \\
\hline none & 1.000 & & & \\
\hline primary & 1.248 & 0.491 & 3.175 & $0.64 I$ \\
\hline secondary & 2.707 & 1.033 & 7.096 & 0.043 \\
\hline college & 10.800 & 3.154 & 36.984 & $<0.001$ \\
\hline
\end{tabular}

*Variables entered on step I: sex, age group, CCF-enrolment and education level of respondent

and through ears and mouth. Of all respondent that knew that the malaria parasites can only enter the human body through mosquito bites $(\mathrm{n}=890), 50 \%$ stated unfavourable hygienic and weather conditions as causes of malaria earlier. More surprisingly, more than half of the respondents that did not cite mosquitoes as cause of malaria earlier identified mosquito bites as the only way that malaria parasites can enter the human body indicating that despite the fact that there is a lot of knowledge in the community, this knowledge is distorted and biomedical relationships not comprehended.

Although over $60 \%$ of the interviewees correctly stated that mosquito bites are responsible for injecting the malaria parasite into the human body, none of the respondents was able to explain correctly where this parasite has been picked up by the mosquito. A common belief was that the parasite comes from various sources of water, bushes, dirty environments, food and air indicating that the cycle of malaria transmission via mosquitoes from a sick person to a healthy one has not been comprehended at all.

Evaluating the community knowledge of the mosquito life cycle $87 \%$ of the respondents $(1,254 / 1,451)$ said they knew where mosquitoes lay their eggs. Places mentioned included stagnant water $(79 \%)$, bushes and grass $(6 \%)$, humid places (4\%) and dark corners (3\%). The majority (65\%) of respondents did not know what mosquito larvae look like and those (35\%) who attempted to define them talked of worm-like invertebrates, small toads, small insects, animals with big heads and small abdomens as well as twinkling reflections in water.

Knowledge of malaria prevention methods differed only slightly between households. Most respondents mentioned more than one method known to them as shown in Table 7; only $4 \%$ of all respondents stated not to know at all how to prevent malaria.

The majority of interviewees had a good theoretical knowledge of how to prevent malaria, with bednets most frequently mentioned. A summary of all methods which community members believed to be useful for preventing malaria is given in Table 7. Notably, clearing vegetation was the second most common method which community members believed to be useful to prevent malaria despite the fact that it is established knowledge in the scientific community that clearing of vegetation is of no benefit but might even worsen the malaria situation [63-67].

Of those that responded to know how to prevent malaria ( $\mathrm{n}=1,398$ ) only $34 \%$ listed solely biomedical correct methods to target either the mosquito adults (bednets, repellents), larvae (destruction of holes with stagnant water) or malaria parasite (drugs); but $72 \%$ listed only correct prevention methods with the one addition of bush clearing. Another 25\% mixed correct knowledge and beliefs e.g. that increased hygiene, disposal of rubbish or keeping warm would help to prevent malaria. Only $3 \%$ of all respondents did not list any scientifically correct malaria prevention measure.

Table 4: Respondents' believed causes of malaria

\begin{tabular}{lrr}
\hline Causes of malaria & $\mathbf{n}$ & $\%$ \\
\hline Total N = I378 & & 90.7 \\
Mosquito bites & 1250 & 30.7 \\
Weather conditions & 423 & 18.1 \\
Lack of hygiene & 250 & 11.3 \\
Bushy compound & 156 & 4.8 \\
Food & 69 & 2.1
\end{tabular}


Table 5: Demographic variables impacting correct knowledge and misconceptions on what causes malaria

\begin{tabular}{|c|c|c|c|c|}
\hline \multirow[t]{2}{*}{ Variables* } & \multirow[t]{2}{*}{ Odds Ratio } & \multicolumn{2}{|c|}{$5 \%$ C.I. for Odds Ratio } & \multirow[t]{2}{*}{$p$} \\
\hline & & Lower & Upper & \\
\hline \multicolumn{5}{|c|}{ Factors associated with knowledge of mosquito bites as sole cause of malaria } \\
\hline \multicolumn{5}{|l|}{ Education* } \\
\hline none & 1.000 & & & \\
\hline primary & 1.473 & 0.910 & 2.385 & 0.115 \\
\hline secondary & 2.837 & 1.681 & 4.787 & $<0.001$ \\
\hline college & 4.400 & 1.615 & 11.990 & 0.004 \\
\hline \multicolumn{5}{|c|}{ Factors associated with belief that unfavourable weather causes malaria } \\
\hline Non-CCF* & 1.488 & 1.172 & 1.890 & 0.001 \\
\hline \multicolumn{5}{|l|}{ Education* } \\
\hline none & 1.000 & & & \\
\hline primary & 0.871 & 0.536 & 1.416 & 0.578 \\
\hline secondary & 0.287 & 0.162 & 0.510 & $<0.001$ \\
\hline college & 0.204 & 0.055 & 0.756 & 0.017 \\
\hline \multicolumn{5}{|c|}{ Factors associated with belief that lack of hygiene causes malaria } \\
\hline \multicolumn{5}{|l|}{ Age* } \\
\hline below 25 & 1.000 & & & \\
\hline 25 to 34 & 0.985 & 0.666 & 1.457 & 0.939 \\
\hline 35 to 44 & 1.175 & 0.775 & 1.783 & 0.448 \\
\hline above 45 & 1.926 & 1.309 & 2.834 & 0.001 \\
\hline \multicolumn{5}{|c|}{ Factors associated with not mentioning mosquito bites as cause of malaria } \\
\hline Non-CCF* & 2.309 & 1.483 & 4.209 & $<0.001$ \\
\hline \multicolumn{5}{|l|}{ Age* } \\
\hline below 25 & 1.000 & & & \\
\hline 25 to 34 & 1.113 & 0.659 & 1.880 & 0.690 \\
\hline 35 to 44 & 1.250 & 0.703 & 2.222 & 0.448 \\
\hline above 45 & 2.694 & 1.578 & 4.600 & $<0.001$ \\
\hline
\end{tabular}

*Variables entered on step I: sex, age group, CCF-enrolment and education level of respondent

The probability of knowing that bednets could be used for malaria prevention was significantly higher in CCFenrolled families than non-CCF families and also increased with increased levels of education. Moreover, people more than 45 years old were less likely to mention bednets than younger people (Table 8).

Source reduction was less likely to be mentioned by nonCCF affiliated community members and women compared to CCF-enrolled members and men, respectively, furthermore it was 3-7 times more commonly mentioned by respondents educated beyond primary level.
Whether respondents mentioned repellents and insecticide use for malaria prevention was confounded by their CCF enrolment status and age. The methods were less likely to be mentioned by respondents not affiliated to CCF and older age groups. Interestingly, the belief that bush clearing can prevent malaria was twice as high in families that were enrolled in CCF compared to non-CCF respondents and more importantly increased significantly with the higher the level of education. Women were less likely to mention bush clearing than men. The probability of believing in measures of general hygiene for malaria prevention increased with being a non-CCF-enrolled

Table 6: Respondents' believed way of parasite infection

\begin{tabular}{lrr}
\hline Ways of parasite entry & $\mathbf{n}$ & $\%$ \\
\hline Total N = I439 & & 999 \\
Mosquito bites & 138 & 69.4 \\
Dirty water or food & 125 & 9.6 \\
Body openings \& cuts & 291 & 8.7 \\
Don't know & 20.2
\end{tabular}


Table 7: Respondents' believed/known and used methods for malaria prevention

\begin{tabular}{|c|c|c|c|c|c|c|}
\hline \multirow[t]{2}{*}{ Methods } & \multicolumn{2}{|c|}{ Methods known } & \multicolumn{2}{|c|}{ Methods used } & \multirow[t]{2}{*}{$\chi^{2}$} & \multirow[t]{2}{*}{$\mathbf{p}^{*}$} \\
\hline & $\mathbf{N}$ & $\%$ & $\mathbf{N}$ & $\%$ & & \\
\hline \multicolumn{7}{|l|}{ Total $N=1451$} \\
\hline Bednets & 1274 & 87.8 & 692 & 47.7 & 528.0 & $<0.001$ \\
\hline Bush clearing & 633 & 43.6 & 492 & 33.9 & 28.4 & $<0.001$ \\
\hline Destruction of burrow pits that can collect water & 492 & 33.9 & 0 & 0.0 & 592.4 & $<0.001$ \\
\hline Burning/spraying insecticide or mosquito repellents & 233 & 16.1 & 236 & 16.3 & 0.1 & ns \\
\hline Boiling/treating water & 186 & 12.8 & 109 & 7.5 & 22.4 & $<0.001$ \\
\hline Taking anti-malarial drugs & 183 & 12.6 & 170 & 11.7 & 0.5 & ns \\
\hline Keeping body/food warm and clean & 170 & 11.7 & 0 & 0.0 & 180.6 & $<0.001$ \\
\hline Proper disposal of empty tins that can hold water & 122 & 8.4 & 309 & 21.3 & 95.3 & $<0.001$ \\
\hline Keeping utensils, house and compound clean & 117 & 8.1 & 38 & 2.6 & 42.5 & $<0.001$ \\
\hline Burning rubbish in the compound & 77 & 5.3 & 42 & 2.9 & 10.7 & 0.010 \\
\hline Use traditional herbs & 48 & 3.3 & 61 & 4.2 & 1.6 & ns \\
\hline None & 52 & 3.6 & 184 & 12.7 & 64.5 & $<0.001$ \\
\hline
\end{tabular}

*d.f. $=1$; for significance $p>0.05$ chi square $\left(\chi^{2}\right)$ should be $\geq 3.84$.

respondent and with older age but decreased with education beyond primary level.

\section{Malaria prevention behaviour}

The actual malaria prevention behaviour practiced by community members differed significantly from the methods known to respondents (Table 7). Despite the fact that $88 \%$ of all interviewees knew that bednets protect from malaria only $58 \%$ used them and in only $48 \%$ (692/ 1,451 ) of the interviewed households could the ownership of one or more nets actually be confirmed. Furthermore, only $37 \%$ of respondents $(535 / 1,451)$ slept under a bednet the night before the interview, which was held during the main malaria transmission season. Of those, most (94\%) said they sleep under a net throughout the year, while a few only used a net when mosquitoes are abundant. Children were the main beneficiaries of bednets: In $88 \%$ of the net-owning households children slept either alone or with their parents under the bednet. In total, 1,073 bednets were found in 692 households serving 4,419 people. This accounts for 1.5 bednets per household or 0.2 bednets per person in bednet-owning households alone.

Consequently, the average bednet coverage for the entire community was 0.7 bednets per household or 0.1 bednet per person which is not enough for a community-level effect [68]. Remarkably, of those respondents that correctly identified mosquito bites as the only means of malaria transmission $(n=642), 48 \%$ did not own a mosquito net while, in contrast, $40 \%$ of those that did not associate malaria with mosquito bites $(n=128)$ owned a net indicating that net ownership does depend on sociodemographic factors other than knowledge alone.
Bush clearing was the second most common method that community members practiced (492/1,451); 51\% defined bush clearing as cutting down all the vegetation on the compound and burning it, $46 \%$ only slashed grass and $3 \%$ characterised it as collecting vegetation and empty containers from the surroundings. 56\% of respondents said they cleared the bush in the last month. The activity was predominantly implemented by men. Of the 492 respondents that practiced bush clearing, 20\% believed that bushes and other vegetation served as larval habitats for mosquitoes and $80 \%$ believed that mosquitoes hide in vegetation and can be prevented from entering the compound by removing it. Most (70\%) said they learned that clearing vegetation prevents malaria in school. Another important source of this information was national and international health care organizations like local extension workers of the Ministry of Health and NGOs, including CCF and UNICEF. Equally worrying, radio and newspaper announcements on malaria control were also cited.

Despite that there was a very good knowledge in the community that the removal of water containing borrow pits protects from malaria, a fact recently highlighted with particular strength in nearby areas [69] nobody actually practiced this. Notably, $13 \%$ of all respondents did nothing to prevent malaria.

While knowledge of prevention measures might be confounded by demographic variables like the age and education level of the respondent, the actual usage of various methods might be decided by the household head and depend on the socio-economic status of the household [70]. The results of logistic regression analyses to investigate this are summarised in Table 9. Socio-economic status had significant impact on the probability of a 
Table 8: Demographic variables impacting correct knowledge and misconceptions about potential methods to prevent malaria

\begin{tabular}{|c|c|c|c|c|}
\hline \multirow[t]{2}{*}{ Variables* } & \multirow[t]{2}{*}{ Odds Ratio } & \multicolumn{2}{|c|}{ 95\% C.I. for Odds Ratio } & \multirow[t]{2}{*}{$p$} \\
\hline & & Lower & Upper & \\
\hline \multicolumn{5}{|c|}{ Factors associated with knowledge of bednets } \\
\hline Non-CCF* & 0.438 & 0.306 & 0.627 & $<0.001$ \\
\hline \multicolumn{5}{|l|}{ Age* } \\
\hline below 25 & 1.000 & & & \\
\hline 25 to 34 & 1.393 & 0.882 & 2.200 & 0.155 \\
\hline 35 to 44 & 1.164 & 0.703 & 1.926 & 0.555 \\
\hline above 45 & 0.525 & 0.327 & 0.844 & 0.008 \\
\hline \multicolumn{5}{|l|}{ Education* } \\
\hline none & 1.000 & & & \\
\hline primary & 2.071 & 1.179 & 3.638 & 0.011 \\
\hline secondary & 3.928 & 1.935 & 7.975 & $<0.001$ \\
\hline college & 542.724 & 0.000 & $1.43 \mathrm{E}+09$ & 0.404 \\
\hline \multicolumn{5}{|c|}{ Factors associated with knowledge of source reduction (filling burrow pits) } \\
\hline Non-CCF* & 0.712 & 0.566 & 0.894 & 0.004 \\
\hline Women* & 0.745 & 0.579 & 0.959 & 0.022 \\
\hline \multicolumn{5}{|l|}{ Education* } \\
\hline none & 1.000 & & & \\
\hline primary & 1.032 & 0.637 & 1.672 & 0.899 \\
\hline secondary & 2.660 & 1.569 & 4.510 & $<0.001$ \\
\hline college & 7.446 & 2.570 & 21.573 & $<0.001$ \\
\hline \multicolumn{5}{|c|}{ Factors associated with knowledge of insecticides and repellents } \\
\hline Non-CCF* & 0.514 & 0.381 & 0.693 & $<0.001$ \\
\hline \multicolumn{5}{|l|}{ Age* } \\
\hline below 25 & 1.000 & & & \\
\hline 25 to 34 & 0.937 & 0.653 & 1.343 & 0.723 \\
\hline 35 to 44 & 0.542 & 0.349 & 0.842 & 0.006 \\
\hline above 45 & 0.576 & 0.376 & 0.883 & 0.011 \\
\hline \multicolumn{5}{|c|}{ Factors associated with belief in bush clearing } \\
\hline Non-CCF* & 0.552 & 0.445 & 0.685 & $<0.001$ \\
\hline Women* & 0.736 & 0.578 & 0.938 & 0.013 \\
\hline \multicolumn{5}{|l|}{ Education* } \\
\hline none & 1.000 & & & \\
\hline primary & 1.602 & 1.007 & 2.551 & 0.047 \\
\hline secondary & 2.431 & 1.454 & 4.067 & 0.001 \\
\hline college & 3.312 & 1.263 & 8.689 & 0.015 \\
\hline \multicolumn{5}{|c|}{ Factors associated with belief in increased hygiene and keeping warm } \\
\hline Non-CCF* & 1.419 & 1.107 & 1.818 & 0.006 \\
\hline \multicolumn{5}{|l|}{ Age* } \\
\hline below 25 & 1.000 & & & \\
\hline 25 to 34 & 1.279 & 0.929 & 1.762 & 0.132 \\
\hline 35 to 44 & 1.335 & 0.937 & 1.903 & 0.110 \\
\hline above 45 & 1.639 & 1.132 & 2.371 & 0.009 \\
\hline \multicolumn{5}{|l|}{ Education* } \\
\hline none & 1.000 & & & \\
\hline primary & 0.639 & 0.394 & 1.037 & 0.070 \\
\hline secondary & 0.544 & 0.316 & 0.937 & 0.028 \\
\hline college & 0.205 & 0.056 & 0.758 & 0.018 \\
\hline
\end{tabular}

*Variables entered on step I: sex, age group, CCF-enrolment and education level of respondent

household owning a bednet, boiling drinking water or not practice any prevention behaviour. Wealthier households were more likely to practice malaria prevention than poorer ones, thus they were more likely to own a bednet and buy fuel for boiling water. Insecticide use, like burning mosquito coils, was independent of the socioeconomic status but women-headed households were more likely to practice this. Proper disposal of tins and rubbish was more likely to be practiced by men-headed households. Clearing vegetation in and around the com- 
pound was expectedly independent of the socio-economic status of the household but was more likely to be practiced by CCF-enrolled than non-enrolled families and men-headed households than women-headed households. Use of anti-malaria drugs was independent of CCF enrolment status, sex of household head and socio-economic status of the household.

\section{Malaria treatment seeking behaviour and associated expenses}

There was a pronounced difference between the theoretical and practical malaria treatment seeking behaviour of community members. In response to the theoretical question 'what do you do if you suspect you or a member of your family has malaria?' 44\% ( $\mathrm{n}=641)$ of interviewees stated they would go to hospital, 54\% would buy drugs or prepare traditional herbs first and go to hospital only if the patient does not get better. One percent made the decision dependent on the availability of cash, if money would be available advice would be sought at hospital otherwise drugs would be bought at a local shop. A few people preferred to pray.

Of all interviewed households $(\mathrm{n}=1,451), 68 \%$ reported a child below the age of five years being sick in the last two weeks. The total expenditure for treating sick children ranged from KShs 2 to 10,000 with a median of KShs 250 (IQR 400). Of the occurring costs, 92\% were spent on drugs and only $5.5 \%$ on laboratory and doctors' fees and $2 \%$ on transport indicating an even lower frequentation of health facilities in practice compared to theory. The remaining $0.5 \%$ was spent on herbalists and traditional herbs. $82 \%$ of respondents with a sick child felt that the disease had negative impacts on their daily life. Women were specifically concerned that they could not run their small-scale businesses and had to neglect farming and domestic work in order to take care of the child. There was no difference in health-seeking behaviour in relation to CCF-enrolment status, education level of respondents or socio-economic status of the households.

Table 9: Socio-economic variables impacting malaria prevention behaviour

\begin{tabular}{|c|c|c|c|c|}
\hline \multirow[t]{2}{*}{ Variables* } & \multirow[t]{2}{*}{ Odds Ratio } & \multicolumn{2}{|c|}{ 95\% C.I. for Odds Ratio } & \multirow[t]{2}{*}{$P$} \\
\hline & & Lower & Upper & \\
\hline \multicolumn{5}{|c|}{ Factors associated with ownership and usage of bednets } \\
\hline \multicolumn{5}{|c|}{ Socio-economic status* } \\
\hline most poor & 1.000 & & & \\
\hline very poor & 1.918 & 1.186 & 3.101 & 0.008 \\
\hline poor & 3.816 & 2.241 & 6.498 & $<0.001$ \\
\hline less poor & 3.640 & 2.205 & 6.008 & $<0.001$ \\
\hline least poor & 6.849 & 3.885 & 12.076 & $<0.001$ \\
\hline \multicolumn{5}{|c|}{ Factors associated with use of insecticides and repellents } \\
\hline Women-headed* & 1.470 & 1.073 & 2.014 & 0.017 \\
\hline \multicolumn{5}{|c|}{ Factors associated with proper disposal of tins and rubbish } \\
\hline Women-headed* & 0.708 & 0.514 & 0.974 & 0.034 \\
\hline \multicolumn{5}{|c|}{ Factors associated with bush clearing } \\
\hline Non-CCF* & 0.687 & 0.547 & 0.864 & 0.001 \\
\hline Women-headed* & 0.564 & 0.424 & 0.751 & $<0.001$ \\
\hline \multicolumn{5}{|c|}{ Factors associated with boiling/treating drinking water } \\
\hline Women-headed* & 1.929 & 1.240 & 3.000 & 0.004 \\
\hline \multicolumn{5}{|c|}{ Socio-economic status* } \\
\hline most poor & 1.000 & & & \\
\hline very poor & 1.807 & 0.889 & 3.673 & 0.102 \\
\hline poor & 2.315 & 1.157 & 4.632 & 0.018 \\
\hline less poor & 2.384 & 1.187 & 4.791 & 0.015 \\
\hline least poor & 2.185 & 1.053 & 4.534 & 0.036 \\
\hline \multicolumn{5}{|c|}{ Factors associated with not practicing any malaria prevention behaviour } \\
\hline Non-CCF* & 1.400 & 1.001 & 1.958 & 0.049 \\
\hline Women-headed* & $1.46 \mathrm{I}$ & 1.000 & 2.134 & 0.050 \\
\hline \multicolumn{5}{|c|}{ Socio-economic status* } \\
\hline most poor & 1.000 & & & \\
\hline very poor & 0.607 & 0.383 & 0.961 & 0.033 \\
\hline poor & 0.699 & 0.444 & 1.099 & 0.121 \\
\hline less poor & 0.430 & 0.258 & 0.717 & 0.001 \\
\hline least poor & 0.469 & 0.282 & 0.781 & 0.004 \\
\hline
\end{tabular}

*Variables entered on step I: CCF-enrolment, sex of household head, socio-economic status 


\section{The role of the community in malaria control}

Most interviewees (939/1,430; 64\%) said that malaria could be controlled on Rusinga island, while 34\% (491/ 1,430 ) did not believe so, with $2 \%$ were undecided. Table 10 summarizes the reasons given for not being able to control malaria. Most of these were based on misconceptions or a fatalistic attitude. With increasing education level respondents were more likely to believe that malaria can be successfully controlled on Rusinga (Table 11).

A number of suggestions were made by respondents who believed that malaria control could be successful on Rusinga ( $\mathrm{n}=939)$ as to what needs to be done (Table 12$)$. People most frequently mentioned that everybody needed to sleep under a mosquito net. This was closely followed by the belief that for successful control everybody on Rusinga would need to clear the vegetation from the compounds and thirdly the drainage of stagnant water and the treatment of larval habitats was mentioned.

Although a large number of community members thought that malaria can be controlled, there seemed to be little that the community felt they could contribute personally and without outside assistance. Moreover, the majority of contributions that were suggested would not even target malaria control (e.g. clearing vegetation, teaching to boil water, collect rubbish, constructing latrines; Table 13). A total of $12 \%(n=243)$ felt they can not personally contribute at all. The most frequently associated benefit with malaria control was that the family would be happier because no-one would be sick and that time and money could be saved for other 'family projects'.

Community members expressed the need to be properly trained on how to prevent malaria during the FGDs and the individual interviews. Only $12.3 \%$ of all interviewees remember receiving malaria-related health education in the past, with CCF being the most frequently-mentioned training partner. In fact trained respondents were twice as likely to have been CCF-enrolled than non-enrolled community members (Odds ratio $=0.493$ (for non-CCF),
95\% C.I. $=0.356-0.682$, d.f. $=1, \mathrm{p}<0.001)$. Other training partners mentioned were the Ministry of Health, churches, schools, the media and local CBOs. Major training components were general cleanliness, collecting tins, clearing vegetation and the use of bednets. Some of those trained said the training had helped them in different ways by encouraging them to drain stagnant water, buy mosquito nets and self-medicate. Others however, said they had financial constraints and had not implemented what they were taught. $72 \%$ of respondents were aware of the malaria project initiated by the RICFP but did not exactly know its goals; the majority demanded to be given free bednets and malaria medication through the project.

\section{Discussion}

The most striking results of the community survey were that malaria is considered one of the major threats to life but that local knowledge about malaria transmission is a chimera of scientific knowledge (e.g. anopheline mosquitoes transmit the disease) and local beliefs (e.g. being rained on, eating sugar cane, or lack of hygiene cause malaria) which combined with impoverishment leads to ineffective malaria prevention. Misconceptions relating to malaria found in this study were remarkably similar to those found elsewhere in Africa [70-75] and other parts of the world $[26,76,77]$. The findings show that there is a high level of what community members term as 'western knowledge' in the Rusinga community which is not completely trusted and, therefore, high priority is still given to traditional beliefs. In a FGD one female participant stated ' $m y$ son has malaria and I believe it is because of the cold and wet weather'. When reminded that only mosquitoes transmit malaria she shook her head and replied 'I have bought a mosquito net for my son and he sleeps under it every night but he was diagnosed with malaria' indicating her scepticism based on the fact that she uses a bednet, but malaria was not prevented as promised. This lack of trust in health messages from 'outside' has been frequently expressed in African communities $[70,74,78]$. Furthermore, a number of contradicting responses during our survey indicate that despite the fact that there is a lot of knowledge in the community, this knowledge was distorted and causal connections were not understood

Table 10: Community's reasons to believe that malaria can not be controlled

\begin{tabular}{|c|c|c|}
\hline Reasons & $\mathbf{n}$ & $\%$ \\
\hline \multicolumn{3}{|l|}{ Total $N=491$} \\
\hline Malaria is a God given fact of life & $|4|$ & 28.7 \\
\hline Impossible to kill all the mosquitoes & 125 & 25.5 \\
\hline People can not afford prevention and treatment & 60 & 12.2 \\
\hline People do not take preventive measures & 53 & 10.8 \\
\hline We are surrounded by the lake (believed breeding habitat) & 48 & 9.8 \\
\hline Malaria multiplies fast and can't be stopped & 23 & 4.7 \\
\hline It is a virus which can not be stopped & 9 & 1.8 \\
\hline There is a lot of dust on Rusinga causing respiratory illness and malaria & 4 & 0.8 \\
\hline No reason & 28 & 5.7 \\
\hline
\end{tabular}


Table I I: Factors associated with belief that malaria can be successfully controlled on Rusinga

\begin{tabular}{|c|c|c|c|c|}
\hline \multirow[t]{2}{*}{ Education* } & \multirow[t]{2}{*}{ Odds Ratio } & \multicolumn{2}{|c|}{ 95\% C.I. for Odds Ratio } & \multirow[t]{2}{*}{$P$} \\
\hline & & Lower & Upper & \\
\hline none & 1.000 & & & \\
\hline primary & 1.619 & 1.048 & 2.499 & 0.037 \\
\hline secondary & 2.878 & 1.754 & 4.722 & $<0.001$ \\
\hline college & 4.644 & 1.463 & 14.749 & 0.010 \\
\hline
\end{tabular}

*Variables entered on step I: sex, age group, CCF-enrolment, education and socioeconomic status

raising questions about the quality of past health education messages and whether they might be more confusing than helpful if not implemented in a cultural sensitive way.

Although many (88\%) knew bednets prevent malaria, only $48 \%$ of households actually owned a net, with only $37 \%$ sleeping under one the previous night. In comparison with other African communities at the time of the survey the bednet coverage was moderate [79]. In contrast to other studies [79] though Rusinga's community had a very high knowledge of children being the most vulnerable to severe malaria and an extremely high coverage of children in bednet-possessing households. This provides an excellent base for increased training on bednet use and availability of nets to protect the target population and reach the Abuja target [80]. In agreement with other studies $[75,81,82]$ bednet ownership was primarily dependent on the socio-economic status of the household. They are luxury assets which are there in better-off households even if the family might have limited knowledge on malaria. Despite Rusinga being a very poor community, a relatively low percentage lived below the poverty line $(15 \%)$ as compared with the entire country (an estimated $50 \%$ of rural dwellers live below the poverty line $[6,83])$. This might be explained by the fact that the majority of inhabitants of Rusinga make a living by trading in fish. It has been shown that fishing families tend to be better-off than their purely farming counterparts in rural areas of western Kenya [83]. Taking these facts into account improving availability of bednets and selling them at reduced costs should help to quickly improve household coverage on Rusinga. During the individual interviews no question was specifically asked about insecticide treatment of the nets. Interestingly though, none of the respondents mentioned insecticide treatment of nets as a malaria prevention measure. During FGDs, most participants were unfamiliar with insecticide treatment of nets (less than $10 \%$ of bednets owners knew their bednet to be treated) and the majority did not know what it would be good for. One FGD with 14 participants was specifically implemented to discuss bednet use and insecticide treatment, and only 2 participants said that insecticide treatment of nets repels mosquitoes from the house. Nobody knew that treated nets kill mosquitoes. The observation that there was little understanding in the community about insecticide treatment of nets despite the fact that there was good knowledge of bednets as a malaria prevention measure and moderate bednet coverage has been frequently reported $[70,71]$ and indicates a gap in explaining to community members the causal connections to comprehend and implement the method.

Table I2: Community's opinion of what needs to be done to control malaria on Rusinga

\begin{tabular}{lc}
\hline Reasons & $\mathbf{n}$ \\
\hline Total N = 939 & $\%$ \\
Everybody needs to sleep under a bednet & 482 \\
Everybody needs to clear vegetation for compound to be open & 346 \\
Stagnant water needs to be drained or treated to kill larvae & 36.8 \\
Government to provide control (including free bednets, larvicide and clearing vegetation) & 258 \\
Everybody to keep compound clean and built latrines & 27.5 \\
Free and proper diagnosis and treatment in hospitals & 9.7 \\
Everybody to take anti-malarial drugs & 8.9 \\
Provision of training on malaria control & 8.4 \\
Provision of access to safe water & 79 \\
Everybody to use preventive measures in the house & 5.1 \\
Malaria vaccine needs to be introduced & 5.5 \\
Living standards need to be improved & 3.5 \\
\hline
\end{tabular}


Table 13: Responses to 'How can YOU contribute to malaria control on Rusinga?'

\begin{tabular}{lr}
\hline Contributions & $\mathbf{n}$ \\
\hline Total N = 939 & $\%$ \\
Personal oriented protection (bednet, insecticides, repellents) & 25.9 \\
If I would be trained I could teach people & 18.1 \\
I can clear vegetation around my house & 17.7 \\
I can advise people to clear vegetation & 16.3 \\
I can teach people to boil water & 7.7 \\
I can participate in removal of empty containers & 7.2 \\
I would actively participate in a program that tells me what to do & 156 \\
I can spay paraffin on waterholes & 72 \\
I can buy medicines and bednets for people & 68 \\
I can help constructing latrines & 0.5 \\
I can only contribute if I am given money & 53 \\
I can not contribute & 0.4 \\
I do not know how I could contribute & 0.3 \\
\end{tabular}

CCF enrolment did not particularly decrease potential vulnerability to malaria, in most cases the knowledge, attitudes and practices in households were not different from those non-enrolled.

Nevertheless, CCF-enrolled families had better knowledge of bednets which is mainly attributed to the fact that CCF had distributed free nets to their families in the past. CCF households were also more aware of stagnant water as mosquito breeding sites but, like others, they did not practice any behaviour to prevent these sites. CCF-enrolment most strikingly increased the implementation of bush clearing for malaria control. In fact, apart from bednet use, the major activity implemented by community members to prevent malaria in Rusinga, as reported elsewhere $[73,75]$, was the clearing of grass and bushes around the compounds and other general sanitation and hygienic measures (e.g. collection of small containers), none of which have a proven efficacy to prevent malaria in Africa. Teaching evidence-based methods needs to take the local ecology of mosquitoes into account [52,84-86] because methods which are appropriate in one area might not be in another. While vegetation clearance can help control shade loving malaria vectors it will increase the abundance of An. gambiae in East Africa which prefers open sun exposed habitats [10,87-90]. That the clearing of bushes removes mosquito adult resting sites and consequently helps prevent malaria has never been proven and is considered ineffective [63-66,91]. An. gambiae is highly anthropophilic and rests primarily inside houses. Outside shelters are difficult to find and are rarely bushes or grass but rather rocks or other artificial shelters like granaries $[92,93]$ which are very darkly shaded [94].

Despite the scientific evidence, bush clearing for malaria control remains 'a remarkably widespread and persistent myth' [64]. Misleading health education messages for community based malaria control can be found for example in the training guidelines of CCF [95] or UNICEF [96] and even in primary and secondary school books [97101] which explains the significantly increased knowledge and practice of this methods in CCF-enrolled and well educated people. Cutting of bushes and grasses around the house and the removal/emptying of small containers from the environment are the primary messages despite none of them serving malaria vectors as oviposition or resting sites. The common application of these practices might be explained by the fact that they do not need any resources and might therefore be dictated by circumstances [73]. Consequently, community based efforts often do not actually target what they intend to do at the outset and changes in educational strategies are necessary to achieve evidence-based malaria prevention behaviour at the community level. More interdisciplinary collaboration between socio-behavioural scientists, education specialists and entomologists would be desirable for designing evidence-based and culturally sensitive interventions and to avoid confusing reports even from the scientific literature $[32,45,102,103]$.

The community hardly distinguished between malaria and other diseases and most illnesses are referred to as malaria. Obvious confusion could be observed with TB and HIV/AIDS as shown by the frequent mention of blood in sputum as a malaria symptom and the fact that $60 \%$ of respondents felt that young adults are at major risk of severe malaria which is most likely associated with the high mortality rate of this age group due to AIDS. Most of the community reacted to illness with self-treatment, which is found in most African communities [73,74,104106]. Treatment is mainly done with modern and rarely with traditional medicine which provides opportunities 
for improvement of drug use through shop keepers training and training on home-based treatment. Most cases of illness are not attended by professional health personnel due to the inaccessibility of health centres and associated costs. This has implications for the impact of national malaria control strategies which mainly target improvement of diagnoses and drugs in government health facilities.

Age and education have been the prime factors responsible for a good knowledge and behaviour. Local beliefs and misconceptions were more frequently expressed by older people. With increase in education, this problem could be overcome given that health messages are developed in a way that they can be trusted by the community. Women are typically the major care givers in the family but were often very poorly educated. Men are in most cases the household heads and decide on how the family resources are spent [70]. Therefore, programmes need to target women and men alike. It is important to note, that the probability of having a better understanding of malaria transmission and control was only significantly increased when the respondents education level went beyond the primary school level. This indicates limited contributions of primary education, which is the major level of education found in the community. In fact, a FGD with primary school teachers revealed basically the same knowledge and misconceptions as the rest of the community (see also [107]). Therefore, primary school teachers need to be included and targeted by the RMP to improve their knowledge to consequently improve school health education. Schools are an important entry point for malaria education $[47,107,108]$ and in a country with over seven million primary school children they present a great opportunity to improve health in the community [32]. The issue of vegetation clearance is currently an examination topic at Kenyan schools, constituting a major problem which urgently needs to be corrected. This calls for the national curriculum reform and retraining of extension workers and revision of standard teaching aids used in schools.

Training in support of malaria control needs to aim at an integrated disease management, even at the individual level. Explanations need to be provided to local communities of causal connections in malaria transmission and control to increase the trust in methodologies. It is important for lay people to understand that a bednet gives you extremely high protection, even more so when insecticidetreated, but can not protect somebody 100\% [109]. Therefore, the implementation of additional evidence-based control methods is vital, like the drying or covering (e.g. through planting of trees and tall reeds) of stagnant water or the mosquito proofing of houses. The latter is a well known and promising method for malaria control [110] which has been conspicuously absent from peoples mind.

The majority of respondents thought that malaria could be controlled on Rusinga Island, and would be willing to contribute in various ways to a community-based malaria control programme. However, they feel that they do need outside assistance which calls for a programme that does encourage and enable the community through evidence based, participatory learning and involvement in programme implementation.

The possible origin of various beliefs and misconceptions about malaria transmission and prevention were investigated during the FGDs in order to find out where they might originate from or how they can be connected to the biomedical context of malaria transmission. The community identified two major groups of beliefs or misconceptions: 1) issues to do with general hygiene and 2) weather conditions and certain type of food. It was discussed that malaria is often a synonym for all type of illnesses in the community and that most health education messages focus on general hygienic conditions like boiling of drinking water, use of latrine and keeping the compound free of rubbish. Since malaria symptoms were felt not to easily distinguish from those of other diseases these general prevention measures of disease were applied to malaria as any other. Furthermore, FGDs and the interviews revealed that despite the relatively high level of awareness that mosquitoes are involved in malaria transmission there was no knowledge at all as to where the malaria parasite gets picked up, which is where unhygienic living conditions serve as an explanation. The second group of believes was discussed after establishing the seasonality of malaria transmission on Rusinga from appearance of stagnant water (larval habitats), to the highest nuisance mosquito biting and the time when most families have sick children in their home. The community members came to realise that most beliefs are associated with the end of the rainy season and beginning of dry season. This is the time when there is considerable rain and sudden changes of weather from cold to hot or vice versa, when people do a lot of physical labour in the fields and when certain crops or fruits are available; but it is also the time of highest biting rates and increasing malaria prevalence. It will, therefore, be useful to include these beliefs in health training activities and develop satisfactory explanations with the community which might lead to a better understanding and higher acceptance of the 'western knowledge' after all.

\section{Conclusion}

There is an urgent need to design culturally sensitive but evidence-based education interventions which take local beliefs into account and which help the community to understand the causal connections between mosquito 
habitats, malaria transmission, malaria symptoms, treatment and prevention. The authors hypothesize that this will be best achieved through participatory, 'hands-on experience' [52], including the community in mapping of larval habitats, studying the mosquito life cycle by rearing them, collecting adult mosquitoes in houses, implementing various vector control strategies and monitoring their impact. Similar approaches have proven highly successful [52] leading to improved malaria prevention behaviour and a decrease in the implementation of inadequate or even exacerbating measures. NGOs, central government education departments and schools have a vital role to play in enabling communities to access appropriate information but need to be equipped with essential knowledge and expert support which could be gained by establishing partnerships with national and international research and tertiary education institutions so that evidence-based research can be applied at the grassroots level [20].

\section{Authors' contributions}

All authors were involved in the design of the study. PO and IK were responsible for the implementation of the study in the field. PO coded the data and supervised data entry. UF and GK analysed the data. UF and PO wrote the first draft of the manuscript. All authors were involved in finalising the manuscript, and read and approved the final version.

\section{Acknowledgements}

We thank all community members of Rusinga who consented to contribute to this survey in FGDs and individual interviews. We are also grateful to the enumerators that implemented the questionnaires for their tireless work in the field. We highly appreciate the administrative and institutional support of Prof. Burt Singer and his team at Princeton University. The support of CCF-Kenya, ICIPE-Mbita and the University of Nairobi is also acknowledged. We thank Prof. Steve Lindsay for the critical review of the manuscript and Prof. Kaneko for the provision of data from the newly established DSS. This project was supported by NIH Research Grant \# R2 I TWO6535 funded by the Fogarty International Center, and the office of Behavioural and Social Sciences Research. GK was supported by the Swiss Tropical Institute. UF was supported by the Environmental Health Project (EHP) of the United States Agency of International Development (USAID).

\section{References}

I. Audibert M, Mathonnat J, Henry MC: Malaria and property accumulation in rice production systems in the savannah zone of Cote d'Ivoire. Trop Med Int Health 2003, 8(5):47I-483.

2. Girardin O, Dao D, Koudou BG, Essé C, Cissé G, Yao T, N'Goran EK, Tschannen AB, Bordmann G, Lehmann B, Nsabimana C, Keiser J, Killeen GF, Singer BH, Tanner M, Utzinger J: Opportunities and limiting factors of intensive vegetable farming in malaria endemic Côte d'Ivoire. Acta Trop 2004, 89(2): 109-123.

3. Sachs J, Malaney P: The economic and social burden of malaria. Nature 2002, 41 5(6872):680-685.

4. Breman JG, Egan A, Keusch GT: The intolerable burden of malaria: a new look at the numbers. Am J Trop Med Hyg 200I, 64(I-2 Suppl):iv-vii.

5. Snow RW, Guerra CA, Noor AM, Myint HY, Hay SI: The global distribution of clinical episodes of Plasmodium falciparum malaria. Nature 2005, 434:214-217.

6. Chuma JM, Thiede M, Molyneux CS: Rethinking the economic costs of malaria at the household level: evidence from apply- ing a new analytical framework in rural Kenya. Malar J 2006, 5:76.

7. Bates I, Fenton C, Gruber J, Lalloo D, Medina Lara A, Squire SB, Theobald $S$, Thomson R, Tolhurst R: Vulnerability to malaria, tuberculosis, and HIVIAIDS infection and disease. Part I: determinants operating at individual and household level. Lancet Infect Dis 2004, 4(5):267-277.

8. Fillinger U, Sonye G, Killeen GF, Knols BG, Becker N: The practical importance of permanent and semipermanent habitats for controlling aquatic stages of Anopheles gambiae sensu lato mosquitoes: operational observations from a rural town in western Kenya. Trop Med Int Health 2004, 9( I 2): I274-I 289.

9. Minakawa N, Sonye G, Yan G: Relationships between occurrence of Anopheles gambiae s.l. (Diptera: Culicidae) and size and stability of larval habitats. J Med Entomol 2005, 42(3):295-300.

10. Munga S, Minakawa N, Zhou G, Mushinzimana E, Barrack $O O$, Githeko AK, Yan G: Association between land cover and habitat productivity of malaria vectors in Western Kenyan highlands. Am J Trop Med Hyg 2006, 74(I):69-75.

II. Mushinzimana E, Munga S, Minakawa N, Li L, Feng CC, Bian L, Kitron U, Schmidt C, Beck L, Zhou G, Githeko AK, Yan G: Landscape determinants and remote sensing of anopheline mosquito larval habitats in the western Kenya highlands. Malar J 2006, 5(I):13.

12. Mutuku FM, Alaii JA, Bayoh MN, Gimnig JE, Vulule JM, Walker ED, Kabiru E, Hawley WA: Distribution, description, and local knowledge of larval habitats of Anopheles gambiae s.l. in a village in western Kenya. Am J Trop Med Hyg 2006, 74(I):44-53.

13. Lindsay SW, Birley M: Rural development and malaria control in sub-Saharan Africa. Ecohealth 2004, I: 129-137.

14. Kitron U, Spielman A: Suppression of transmission of malaria through source reduction: antianopheline measures applied in Israel, the United States, and Italy. Rev Infect Dis 1989, II (3):39I-406.

15. Townson H, Nathan MB, Zaim M, Guillet P, Manga L, Bos R, Kindhauser M: Exploiting the potential of vector control for disease prevention. Bull World Health Organ 2005, 83(1 2):942-947.

16. van den Berg H, Knols BG: The Farmer Field School: a method for enhancing the role of rural communities in malaria control? Malar J 2006, 5(I):3.

17. Yapabandara AM, Curtis CF: Control of vectors and incidence of malaria in an irrigated settlement scheme in Sri Lanka by using the insect growth regulator pyriproxyfen. J Am Mosq Control Assoc 2004, 20(4):395-400.

18. Yapabandara AM, Curtis CF, Wickramasinghe MB, Fernando WP: Control of malaria vectors with the insect growth regulator pyriproxyfen in a gem-mining area in Sri Lanka. Acta Trop 200I, 80(3):265-276.

19. Brieger WR: Health education to promote community involvement in the control of tropical diseases. Acta Trop 1996, 6I(2):93-106.

20. Mukabana WR, Kannady K, ljumba J, Mathenge E, Kiche I, Nkwengulila G, Mboera L, Mtasiwa D, Yamagata Y, van Schayk I, Knols BG, Lindsay SW, Caldas de Castro M, Mshinda H, Tanner M, Fillinger U, Killeen GF: Ecologists can enable communities to implement malaria vector control in Africa. Malar J 2006, 5(I):9.

21. Rifkin SB: Paradigms lost: toward a new understanding of community participation in health programmes. Acta Trop 1996, 61 (2):79-92.

22. Williams HA, Jones CO: A critical review of behavioral issues related to malaria control in sub-Saharan Africa: what contributions have social scientists made? Soc Sci Med 2004, 59(3):50I-523.

23. Manderson L: Community participation and malaria control in Southeast Asia: defining the principles of involvement. Southeast Asian I Trop Med Public Health 1992, 23 Suppl I:9-17.

24. RBM: Roll Back Malaria: Global strategic plan 2005-2015 . Geneva ; 2005: I-44

25. Sornmani S: Current knowledge of risk behavior and risk factors in malaria in Southeast Asia. Southeast Asian J Trop Med Public Health 1992, 23 Suppl I:6-8.

26. Kroeger A, Meyer R, Mancheno M, Gonzalez M: Health education for community-based malaria control: an intervention study in Ecuador, Colombia and Nicaragua. Trop Med Int Health 1996 , I(6):836-846 
27. Kidson C: Social and behavioural aspects of malaria control. In Southeast Asian Journal of Tropical Medicine and Public Health 1992. 23 Suppl I:I-6I.

28. Gubler DJ, Clark GG: Community involvement in the control of Aedes aegypti. Acta Trop 1996, 6 I (2): 169-179.

29. Parry J, Wright J: Community participation in health impact assessments: intuitively appealing but practically difficult. Bull World Health Organ 2003, 8 I(6):388.

30. Reeder JC, Taime J: Engaging the community in research: lessons learned from the malaria vaccine trial. Trends Parasitol 2003, I9(6):28I-282.

31. Kay B, Vu SN: New strategy against Aedes aegypti in Vietnam. Lancet 2005, 365(9459):613-617.

32. Onyango-Ouma W, Aagaard-Hansen J, Jensen BB: The potential of schoolchildren as health change agents in rural western Kenya. Soc Sci Med 2005, 6 I (8): I71 I-I722.

33. Cairncross S, Braide El, Bugri SZ: Community participation in the eradication of guinea worm disease. Acta Trop 1996 6 I(2): $|2|-136$.

34. Hopkins DR, Ruiz-Tiben E, Downs P, Withers PC Jr., Maguire JH: Dracunculiasis eradication: the final inch. Am J Trop Med Hyg 2005, 73(4):669-675.

35. Richards F Jr., Gonzales-Peralta C, Jallah E, Miri E: Community based ivermectin distributors: onchocerciasis control at the village level in Plateau State, Nigeria. Acta Trop 1996 , 6 I(2): I37-144.

36. Boelee E, Laamrani H: Environmental control of schistosomiasis through community participation in a Moroccan oasis. Trop Med Int Health 2004, 9(9):997-1004.

37. Cline BL, Hewlett BS: Community-based approach to schistosomiasis control. Acta Trop 1996, 6 I(2): I07-II9.

38. Kaseje DC, Spencer HC: The Saradidi, Kenya, rural health development programme. Ann Trop Med Parasitol 1987, 8 I Suppl I: I-12.

39. Govere J, Durrheim D, la Grange K, Mabuza A, Booman M: Community knowledge and perceptions about malaria and practices influencing malaria control in Mpumalanga Province, South Africa. SAfr Med J 2000, 90(6):6II-6I6

40. Cunha ML, Piovesan-Alves F, Pang LW: Community-based program for malaria case management in the Brazilian Amazon. Am J Trop Med Hyg 200I, 65(6):872-876.

41. Ghebreyesus TA, Alemayehu T, Bosman A, Witten KH, Teklehaimanot A: Community participation in malaria control in Tigray region Ethiopia. Acta Trop 1996, 6 I(2): I45-I56.

42. Kaona FA, Tuba $M$ : Improving ability to identify malaria and correctly use chloroquine in children at household level in Nakonde District, Northern Province of Zambia. Malar 2003, 2(I):43.

43. Nyarango PM, Gebremeskel T, Mebrahtu G, Mufunda J, Abdulmumini U, Ogbamariam A, Kosia A, Gebremichael A, Gunawardena D, Ghebrat $Y$, Okbaldet $Y$ : A steep decline of malaria morbidity and mortality trends in Eritrea between 2000 and 2004: the effect of combination of control methods. Malar J 2006, 5:33.

44. Okanurak K, Ruebush TK 2nd: Village-based diagnosis and treatment of malaria. Acta Trop 1996, 6 I(2): I57-I67.

45. Nkuo Akenji TK, Ntonifor NN, Ching JK, Kimbi HK, Ndamukong KN, Anong DN, Boyo MG, Titanji VP: Evaluating a malaria intervention strategy using knowledge, practices and coverage surveys in rural Bolifamba, southwest Cameroon. Trans $R$ Soc Trop Med Hyg 2005, 99(5):325-332.

46. Tavrow P, Shabahang J, Makama S: Vendor-to-vendor education to improve malaria treatment by private drug outlets in Bungoma District, Kenya. Malar J 2003, 2: 10.

47. Marsh VM, Mutemi W, Some ES, Haaland A, Snow RW: Evaluating the community education programme of an insecticidetreated bed net trial on the Kenyan coast. Health policy and planning |996, I I(3):280-29|.

48. Freeman T: Community-based malaria control in Zimbabwe. Bull World Health Organ 1999, 77(3):295-296.

49. Vanek MJ, Shoo B, Mtasiwa D, Kiama M, Lindsay SW, Fillinger U, Kannady K, Tanner M, Killeen GF: Community-based surveillance of malaria vector larval habitats: a baseline study in urban Dar es Salaam, Tanzania. BMC public health [electronic resource] 2006, 6: 154 .

50. Yohannes M, Haile M, Ghebreyesus TA, Witten KH, Getachew A Byass $\mathrm{P}$, Lindsay SW: Can source reduction of mosquito larval habitat reduce malaria transmission in Tigray, Ethiopia? Trop Med Int Health 2005, I O( I 2): I 274- 1285

51. Okanurak K, Sornmani S: Community participation in the malaria control program in Thailand: a review. Southeast Asian J Trop Med Public Health 1992, 23 Suppl I:36-43.

52. Yasuoka J, Mangione TW, Spielman A, Levins R: Impact of education on knowledge, agricultural practices, and community actions for mosquito control and mosquito-borne disease prevention in rice ecosystems in Sri Lanka. Am J Trop Med Hyg 2006, 74(6): $1034-1042$.

53. Schultz LJ, Ettling M, Chitsulo L, Steketee RW, Nyasulu Y, Macheso A, Nwanyanwu OC: A nation-wide malaria knowledge, attitudes and practices survey in Malawi: objectives and methodology. Trop Med Parasitol 1994, 45(1):54-56.

54. Fillinger U, Lindsay SW: Suppression of exposure to malaria vectors by an order of magnitude using microbial larvicides in rural Kenya. Trop Med Int Health 2006, I I ( I I): I 629- I642.

55. Minakawa N, Mutero CM, Githure JI, Beier JC, Yan G: Spatial distribution and habitat characterization of anopheline mosquito larvae in Western Kenya. Am J Trop Med Hyg 1999, 6I(6): $1010-1016$

56. Mutero CM, Ouma JH, Agak BK, Wanderi JA, Copeland RS: Malaria prevalence and use of self-protection measures against mosquitoes in Suba district. East African Medical Journal 1998, 75(1): II-16.

57. GoK: Poverty Reduction Strategy Paper for the period 200 I2004. Nairobi , Government of the Republic of Kenya, Ministry of Finance and Planning; 200I.

58. GoK: Suba District PRSP: Consultation Report for the period 200I-2004. Government of the Republic of Kenya, Ministry of Finance and Planning; 200I.

59. CCF: Building stronger communities in Kenya. [http:// www.christianchildrensfund.org/content.aspx?id=229]

60. Mensah OA, Kumaranayake L: Malaria incidence in rural Benin: does economics matter in endemic area? Health policy (Amsterdam, Netherlands) 2004, 68(I):93-102.

6I. Worral E, Basu S, Hanson K: The relationship between socioeconomic status and malaria: a review of the literature. HEFP working paper 0I/03 LSHTM 2003.

62. Schellenberg JA, Victora CG, Mushi A, De Savigny D, Schellenberg D Mshinda $\mathrm{H}$, Bryce J: Inequities among the very poor: health care for children in rural southern Tanzania. The Lancet 2003 , 36 I:56 I-566.

63. Hacket LW, Russell PF, Scharff JW, White R: The present use of naturalistic measures in the control of malaria. Bulletin of the Health Organization of the League of Nations 1938, 7:1016-1064.

64. Lines J: How to grow mosquitoes in African towns. Waterlines 2002, 20(4): 16-18.

65. Ribbands CR: Effects of bush clearance to flighting of West African anophelines. Bull Entomol Res 1946, 37:33-4I.

66. Stephens C, Masamu ET, Kiama MG, Keto AJ, Kinenekejo M, Ichimori $\mathrm{K}$, Lines J: Knowledge of mosquitos in relation to public and domestic control activities in the cities of Dar es Salaam and Tanga. Bull World Health Organ 1995, 73(I):97-104.

67. Briet OJ, Dossou-Yovo J, Akodo E, van de Giesen N, Teuscher TM: The relationship between Anopheles gambiae density and rice cultivation in the savannah zone and forest zone of Cote d'Ivoire. Trop Med Int Health 2003, 8(5):439-448.

68. Hawley WA, Phillips-Howard PA, ter Kuile FO, Terlouw DJ, Vulule JM, Ombok M, Nahlen BL, Gimnig JE, Kariuki SK, Kolczak MS, Hightower AW: Community-wide effects of permethrin-treated bed nets on child mortality and malaria morbidity in western Kenya. Am J Trop Med Hyg 2003, 68(4 Suppl): I $21-127$.

69. Mutuku FM, Bayoh MN, Gimnig JE, Vulule JM, Kamau L, Walker ED, Kabiru E, Hawley WA: Pupal habitat productivity of Anopheles gambiae complex mosquitoes in a rural village in western Kenya. Am / Trop Med Hyg 2006, 74(I):54-6I.

70. Alaii JA, van den Borne HW, Kachur SP, Mwenesi H, Vulule JM, Hawley WA, Meltzer MI, Nahlen BL, Phillips-Howard PA: Perceptions of bed nets and malaria prevention before and after a randomized controlled trial of permethrin-treated bed nets in western Kenya. Am J Trop Med Hyg 2003, 68(4 Suppl):|42-|48.

7I. Okrah J, Traore C, Pale A, Sommerfeld J, Muller O: Community factors associated with malaria prevention by mosquito nets: an exploratory study in rural Burkina Faso. Trop Med Int Health 2002, 7(3):240-248. 
72. Ahorlu CK, Koram KA, Ahorlu C, de Savigny D, Weiss MG: Community concepts of malaria-related illness with and without convulsions in southern Ghana. Malar J 2005, 4:47.

73. Oguonu T, Okafor HU, Obu HA: Caregivers's knowledge, attitude and practice on childhood malaria and treatment in urban and rural communities in Enugu, south-east Nigeria. Public health 2005, I I 9(5):409-4 I 4.

74. Nuwaha F: People's perception of malaria in Mbarara, Uganda. Trop Med Int Health 2002, 7(5):462-470.

75. De La Cruz N, Crookston B, Dearden K, Gray B, Ivins N, Alder S, Davis R: Who sleeps under bednets in Ghana? A doer/nondoer analysis of malaria prevention behaviours. Malar J 2006, 5:61

76. Simsek Z, Kurcer MA: Malaria: knowledge and behaviour in an endemic rural area of Turkey. Public health 2005 I I 9(3):202-208

77. Nieto T, Mendez F, Carrasquilla G: Knowledge, beliefs and practices relevant for malaria control in an endemic urban area of the Colombian Pacific. Soc Sci Med 1999, 49(5):601-609.

78. Winch PJ, Makemba AM, Kamazima SR, Lurie M, Lwihula GK, Premji Z, Minjas JN, Shiff CJ: Local terminology for febrile illnesses in Bagamoyo District, Tanzania and its impact on the design of a community-based malaria control programme. Soc Sci Med 1996, 42(7): 1057-1067

79. Korenromp EL, Miller J, Cibulskis RE, Kabir Cham M, Alnwick D, Dye $C$ : Monitoring mosquito net coverage for malaria control in Africa: possession vs. use by children under 5 years. Trop Med Int Health 2003, 8(8):693-703.

80. WHO: African summit on Roll Back Malaria, Abuja, Nigeria WHO/CDS/RBM/2000.I7. Geneva, WHO; 2000.

81. Howard N, Chandramohan D, Freeman T, Shafi A, Rafi M, Enayatullah $S$, Rowland M: Socio-economic factors associated with the purchasing of insecticide-treated nets in Afghanistan and their implications for social marketing. Trop Med Int Health 2003 , 8(12): I043-1050.

82. Onwujekwe O, Hanson $\mathrm{K}$, Fox-Rushby J: Inequalities in purchase of mosquito nets and willingness to pay for insecticidetreated nets in Nigeria: challenges for malaria control interventions. Malar J 2004, 3:6.

83. Freeman HA, Ellis $\mathrm{F}$, Allison $\mathrm{E}$ : Livelihoods and rural poverty reduction in Kenya. Development Policy Review 2004, 22(2): |47-|7|.

84. McArthur J: The control of malaria in Borneo. Trans $R$ Soc Trop Med Hyg 1954, 48(3):234-24l.

85. Watson M: The prevention of malaria in the Federated Malay States. Liverpool, Liverpool School of Tropical Medicine; I91 I.

86. Watson M: African Highway. London, John Murray; 1 953:294.

87. Hancock GLR: The mosquitoes of Namanve swamp, Uganda. J Anim Ecology 1934, 3(2):204-221.

88. Hopkins MA: Afforestation as a method of drying up swamps. East African Medical Journal 1940, I 7:189-194.

89. Jepson WF, Moutia A, Courtois C: The malaria problem in Mauritius: the bionomics of Mauritian anophelines. Bull Entomol Res 1947, 38: 177-208.

90. Minakawa N, Munga S, Atieli F, Mushinzimana E, Zhou G, Githeko AK, Yan G: Spatial distribution of anopheline larval habitats in Western Kenyan highlands: effects of land cover types and topography. Am J Trop Med Hyg 2005, 73(I): I57-165.

91. Blacklock DB: Studies in rural hygiene in the tropics. The cultivation of dense shade plants as an anti-malaria measure. Ann Trop Med Parasitol 1936, 30:181-185.

92. Githeko AK, Service MW, Mbogo CM, Atieli FK: Resting behaviour, ecology and genetics of malaria vectors in large scale agricultural areas of Western Kenya. Parassitologia 1996, 38(3):48I-489.

93. Odiere; M, Bayoh; MN, Gimnig J, Vulule J, Irungu L, Walker E: Sampling outdoor resting Anopheles gambiae and other mosquitoes (Diptera: Culicidae) in western Kenya with clay pots . J Med Entomol 2007, 44(I): 14-22.

94. Gillies MT: Studies of house leaving and outside resting of Anopheles gambiae and Anopheles funestus in East Africa. I. The outside resting population. Bull Entomol Res 1954 45:36I-374

95. CCF: Health and nutrition program training manual. Nairobi , CCF Kenya; 200I.
96. UNICEF: Facts for life - malaria supporting information. [http://www.unicef.org/ffl//0/].

97. Kagunda J, Onjolo OJ, Sabwa D, Agufana R: Foundation Science Pupils book 6. Nairobi, The Jomo Kenyatta Foundation; 2003:I-8.

98. KIE: Secondary Home Science, Form four pupils book. Nairobi , Kenya Literature Bureau; 2002:I-66.

99. Muchiri PM: Principles of biology, Forms 3 and 4, Vol. 2. Nairobi , Pezi publishers; 2003.

100. Stone RH, Cozens AB: New biology for tropical schools. 3rd edition. London, Longman; 2002:1-37.

I0I. Vashista KS, Patel NM: Learning science for standard four, upper primary series. Nairobi, Malimu Publications; 2002:I-83.

102. Macintyre K, Keating J, Sosler S, Kibe L, Mbogo CM, Githeko AK, Beier JC: Examining the determinants of mosquito-avoidance practices in two Kenyan cities. Malar J 2002, I(I): |4.

103. Muula AS, Chimalizeni Y: Knowledge, attitudes and practices towards malaria among primary school pupils in Ndirande, Blantyre, Malawi. Trop Doct 2004, 34(2):90-93.

104. Nyamongo IK: Home case management of malaria: an ethnographic study of lay people's classification of drugs in Suneka division, Kenya. Trop Med Int Health 1999, 4(I I):736-743.

105. Nyamongo IK: Health care switching behaviour of malaria patients in a Kenyan rural community. Soc Sci Med 2002, 54(3):377-386.

106. de Savigny D, Mayombana C, Mwageni E, Masanja H, Minhaj A, Mkilindi Y, Mbuya C, Kasale H, Reid G: Care-seeking patterns for fatal malaria in Tanzania. Malar J 2004, 3:27.

107. Elzubier AG, Ansari EH, el Nour MH, Bella H: Knowledge and misconceptions about malaria among secondary school students and teachers in Kassala, eastern Sudan. J R Soc Health 1997, I | 7(6):38|-385

108. Bhati PG, Kant R, Srivastava HC, Malaviya VS, Pujara PK: Role of health education in school-children with particular reference to malaria. Indian I Malariol I995, 32(3):93-98.

109. Killeen GF, Kihonda J, Lyimo E, Oketch FR, Kotas ME, Mathenge E, Schellenberg JA, Lengeler C, Smith TA, Drakeley C): Quantifying behavioural interactions between humans and mosquitoes: evaluating the protective efficacy of insecticidal nets against malaria transmission in rural Tanzania. BMC infectious diseases 2006, 6: 161 .

I 10. Lindsay SW, Jawara M, Paine K, Pinder M, Walraven GE, Emerson PM: Changes in house design reduce exposure to malaria mosquitoes. Trop Med Int Health 2003, 8(6):5I2-5I7.
Publish with Biomed Central and every scientist can read your work free of charge

"BioMed Central will be the most significant development for disseminating the results of biomedical research in our lifetime. "

Sir Paul Nurse, Cancer Research UK

Your research papers will be:

- available free of charge to the entire biomedical community

- peer reviewed and published immediately upon acceptance

- cited in PubMed and archived on PubMed Central

- yours - you keep the copyright
BioMedcentral 